\title{
Factors Associated with Farmers' Perception towards Climate Change in Pokhara
}

\author{
Ananta Raj Dhungana \\ School of Development and Social Engineering, Pokhara University \\ Email: anantastat@gmail.com
}

Article History

Received 21 August $2018 \quad$ Revised 29 September $2018 \quad$ Accepted 30 November 2018

\begin{abstract}
Climate change is one of the major concerns among the researchers in twenty first century .This study aims to analyze the factors associated with farmers' perception towards climate change in Pokhara. For this purpose, two wards of Pokhara i.e. ward no. 30and ward no. 33were selected purposively. Out of 3982 households in these wards, 216 households are proportionately distributed in these wards. Information was collected by using structured questionnairethrough interview techniques with household head or a household member having age 40 years and over and residing in that locality since last 10 years. A systematic sampling technique was carried out to select the samples. Chi-squared test was applied to find the factors associated with farmers' perception towards climate change. All the respondents were aware about the climate change and received information about climate change from radio, television, newspaper, peer groups. Majority of the respondents claim that climate change has been occurred in temperature, annual summer hotness, decrease in average annual rainfall, no change in average annual draught incidents, no change in flood incidents, no change in water availability to irrigate and increase in average number of pest and plant disease attack. It is found that there is significant association between farmer's perception level towards climate change with agriculture skill of the respondents, caste/ethnicity, major occupation and sex. Hence agriculture skill, sex, caste/ethnicity and occupations of the respondents are the major factors associated with farmers' perception towards climate change.
\end{abstract}

Key words: Agriculture, climate change, farmer, perception

(C) The Author, published by JRCC, Janapriya Multiple Campus

ISSN 2362-1516 


\section{Introduction}

Climate change refers to a change in the state of the climate that can be identified (e.g. using statistical tests) by changes in the mean and/or the variability of its properties, and that persists for an extended period, typically decades or longer (IPCC, 2007). A heavy reliance on tourism and agriculture makes Nepal's economy very sensitive to climate variability (CBS, 2011). Agriculture is the main source of food, income and employment for the majority (65.7\%) of the population of Nepal (CBS, 2014). About 33 percent of its GDP and more than 50 percent of its export depend on agriculture. Poorest population are involved in agriculture (Satyal, 2010). Agronomic research indicates that higher temperatures associated with climatic change will be very harmful to the production of many crop and livestock groups (Gitay et al., 2001 and Easterling et al., 2007). The average temperature of Nepal is increasing at the rate of approximately 0.06 degrees Celsius per year (Malla, 2008). Increased level of CO2 and temperature have negative impact on nutrient components of the crops (CBS, 2016). It is obvious that people in drought and flood-affected communities have evolved their own adaptation strategies to protect their families, assets and secure food security (Agrawal, McSweeney, \& Perrin, 2008; Odjugo, 2010). Moreover, previous studies by various scholars, including Maddison (2006), Ishaya and Abaje (2008), Paavola (2008), Mutekwa (2009) and Lema and Majule (2009) have reported farmer observations of climate change and existing adaptation strategies for managing climate risks, for example, proper timing of agricultural operations and use of different crop varieties. Perception is recognized to be the precondition for adaptation to climate change and variability. It is one among the factors that can influence farmer's decision whether to adapt or not to climate change and variability as they determine decisions of the farmers in management of agricultural activities. Several studies on climate change had revealed that most farmers now perceived the occurrences of CC \& V (Maddison, 2006; Gbetibouo, 2009;Kashaigili et al., 2014). In countries like Senegal, China, Ghana, Nepal, Bangladesh, Nigeria, United States of America, farmers have been mentioned to perceive and even adapt to changes in the climate (Mertz et al., 2009; Byg\&Salick, 2009; Fosu-Mensah et al., 2010; Maharjan et al., 2011; Haque et al., 2011; Salau, 2012; Arbuckle et al., 2013). Socioeconomic and environmental factors have been demonstrated in various studies to influence farmers' perception and adaptation to changes in the climate (Deressa et al, 2011), those include education, household size, livestock ownership, agro-ecological zone, farm size and access to credit 
among others.

The impact of climate change (CC) on water resources is likely to affect agricultural systems and food security. This is especially critical in a least developed country (LDC) like Nepal where a high percentage of the population is dependent on agriculture for its livelihoods. While this information on farmers' perceptions on climate change and variability has been more evident, there have not been done sufficiently such type of study in the particular area of mid hill part of Nepal. In overall climate change trend Kaskihas identified as very high risk (0.580-1.00) (NAPA, 2010). Therefore, this study aims to fill the gap for exploring the perception of people towards climate change and factors associated with perception in Pokhara valley, Nepal.

\section{Data and Methods}

This study aims to explore the perception of people on climate change and associated factors, both exploratory and analytical type of research design was applied for this study. Quantitative data with primary source was used for this study. A multistage Sampling technique was adopted for choosing the study units. In overall, climate change trend of Kaski have been identified as very high risk (0.580-1.00) (NAPA, 2010). So, at first mid hill part of western Nepal i.e.Kaski District is selected purposively. At second stage, as ward no. 33 of Pokhara Metropolitan City(which was previously rural VDC) which is still rural setting of Kaski and ward no. 30 which is semi-urban setting are selected purposively. From 3982 households of these wards, 216 households ( at 6.5 percent margin of error and 5 percent level of significance) are proportionately distributed in wards 30 and 33 as 82 and 134 respectively. At final stage, 216 respondents(household head or household member having age 40 years and over and residing in that locality since last 10 years)were considered as the ultimate respondents for interview and were selected by using systematic sampling techniques. The quantitative data was collected by using structured questionnaire. Pre-test was carried out in the similar settings of these wards among 22 respondents before finalizing the questionnaire. Verbal informed consent was obtained from the participants. Purpose of data collection was explained to the respondents before interviewing. Privacy and confidentiality of all respondents are maintained regarding their information.

For this study, farmers' perception towards climate change is considered as dependent variable and age of household head, gender of household head, education of household head, major occupation, 
caste/ethnicity,agricultural skill and farming experiences are taken as independent variables. Chisquared test was applied for finding the associated factors with the level of farmer's perception towards climate change.

\section{Results and Discussion}

Based on the information collected from 216 responds, we have the following results and discussions:

\section{Awareness and Means of Information about Climate Change}

All the respondents are aware about the climate change and received information about climate change from radio, television, newspaper, peer groups and others. More than ninety percent of the respondents received information about climate change from radio followed by peer groups $(88.4 \%)$, radio $(67.1 \%)$, newspaper $(59.7 \%)$ and others $(18.5 \%)$. It looks that television and peer groups are the major means for delivering the information regarding climate change.

Table 1

Means of Information about Climate Change

\begin{tabular}{lcc}
\hline Means of Information & Responses & Percent \\
\hline Radio & 145 & 67.1 \\
TV & 199 & 92.1 \\
Newspaper & 129 & 59.7 \\
Peer Groups & 191 & 88.4 \\
Others & 40 & 18.5
\end{tabular}

Source: Field Survey, 2018

\section{Perception towards Climate Change}

It is found that all the respondents noticed or perceived climate change during the last ten years.

\section{Annual Average Temperature}

Regarding the perception towards annual average temperature, almost all the respondents responded that there is increase in the annual average temperature. This result is same with the study of Udin 
et al. (2017). Very few respondents view was decrease (1.4\%) and no change $(0.5 \%)$. This result is similar to the study of Ndamani and Watanabe (2015) regarding Farmers' perceptions about adaptation practices to climate change and barriers to adaptation: A micro-level study in Ghana.

Table 2

Annual Average Temperature

\begin{tabular}{lcc}
\hline Annual average temperature & Frequency & Percent \\
\hline Increase & 212 & 98.1 \\
Decrease & 3 & 1.4 \\
No Change & 1 & .5 \\
Total & 216 & 100.0 \\
\hline
\end{tabular}

Source: Field Survey, 2018

\section{Annual average Summer Hotness}

Regarding the perception towards annual summer hotness, almost all the respondents responded that there is increase in the annual average summer hotness. Very few respondents' view was decrease $(2.8 \%)$ and no change $(0.5 \%)$.

Table 3

Annual Average Summer Hotness

\begin{tabular}{lcc}
\hline Annual average summer hotness & Frequency & Percent \\
\hline Increase & 209 & 96.8 \\
Decrease & 6 & 2.8 \\
No Change & 1 & .5 \\
Total & 216 & 100.0
\end{tabular}

Source: Field Survey, 2018

\section{Annual Average Rainfall}

Regarding the perception towards annual average rainfall, more than two fifth of the respondents (45.4\%) responded that there is decrease in the annual average rainfall. More than two third of the respondents $(36.6 \%)$ responded as no change followed by an increase (14.8\%) and don'tknow 
$(3.2 \%)$ respectively. Here the majority of the respondents perceived a decrease in rainfall which is similar to the study of Ndamani and Watanabe (2015), Udin et al. (2017) regarding Farmers' perceptions about adaptation practices to climate change and barriers to adaptation: A micro-level study in Ghana.

Table 4

Annual Average Rainfall

\begin{tabular}{lcc}
\hline Annual average rainfall & Frequency & Percent \\
\hline Increase & 32 & 14.8 \\
Decrease & 98 & 45.4 \\
No Change & 79 & 36.6 \\
Don't Know & 7 & 3.2 \\
Total & 216 & 100.0 \\
\hline
\end{tabular}

Source: Field Survey, 2018

\section{Annual Average Draught Incidents and Flood Incidents}

Regarding the perception towards annual draught incidents, more than two fifth of the respondents $(45.8 \%)$ responded that they perceived no change in the average draught incidents. More than one fourth of the respondents $(28.7 \%)$ responded as an increase in the annual draught incidents followed by decrease (20.8\%) and don't know (4.6\%) respectively. Further more than half of the respondents $(52.3 \%)$ responded that they perceived no change in average flood incidents. More than one fourth $(27.3 \%)$ perceived as decrease followed by don't know (11.1\%) and increase $(8.3 \%)$ respectively.

Table 5

Annual Average Draught Incidents and Flood Incidents

\begin{tabular}{lcc}
\hline Annual average draught incidents & Frequency & Percent \\
\hline Increase & 62 & 28.7 \\
Decrease & 45 & 20.8 \\
No Change & 99 & 45.8 \\
Don't Know & 10 & 4.6 \\
Average flood incidents & & \\
Increase & 18 & 8.3 \\
\hline Decrease & 59 & 27.3
\end{tabular}


No Change

Don't Know
115

24

216

216

53.2

11.1

\section{Total}

100.0

Source: Field Survey, 2018

\section{Water Availability to Irrigate the Fields and Average Number of Pest \& Plant Disease Attack}

Regarding the perception towards water availability to irrigate the fields, almost two fifth of the respondents $(39.4 \%)$ responded that they perceived no change in the availability of water to irrigate the fields. Almostone third of the respondents (32.9\%) responded as an increase in the availability of water followed by decrease $(22.2 \%)$ and don't know (5.6\%) respectively. Further almost all the respondents $(96.3 \%)$ responded that they perceived increase in the average number of pest and plant disease attack on the agriculture. Very few perceived as no change (2.3\%) and decrease (1.4\%).

Table 6

Water Availability to Irrigate the Fields and Average Number of Pest \& Plant Disease Attack

\begin{tabular}{lcc}
\hline Water availability to irrigate & Frequency & Percent \\
\hline Increase & 71 & 32.9 \\
Decrease & 48 & 22.2 \\
No Change & 85 & 39.4 \\
Don't Know & 12 & 5.6 \\
Average number of pest and plant disease attack & & \\
Increase & 208 & 96.3 \\
Decrease & 3 & 1.4 \\
No Change & 5 & 2.3 \\
Total & 216 & 100.0 \\
\hline
\end{tabular}

Source: Field Survey, 2018

\section{Level of perception of the farmers towards climate change}

To find the level of perception of the farmers towards climate change, all the indicators of the farmer's perception towards climate change, i.e., annual average temperature, annual average summer hotness, annual average rainfall, annual average draught incidents, flood incidents, water availability to irrigate and average number of pest and plant disease attackwere taken at once and 
the total score is calculated. Then the total score is divided by the total highest score of the indicators to find the individual mean score (IMS). Then the mean and standard deviation of IMS of 216 respondents are calculated i.e. it is found to be 0.5531 and 0.0645 respectively. The IMS value less than (mean \pm S.D.) is considered as low level. The IMS value more than (mean \pm S.D.) is considered as high level and the IMS value within (mean \pm S.D.) is considered as medium level.Finally frequency analysis is carried out and the output is shown in table no. 7.

Table 7

Farmer's Perception Level towards Climate Change

\begin{tabular}{lcc}
\hline Level & Number & Percent \\
\hline Low & 29 & 13.4 \\
Medium & 165 & 76.4 \\
High & 22 & 10.2 \\
Total & 216 & 100.0 \\
\hline
\end{tabular}

Source: Field Survey, 2018 and Authors Calculation

Out of 216 respondents, more than three fifth of the respondents $(76.4 \%)$ have medium level of perception toward s climate change followed by low (13.4\%) and high (10.2) respectively. It shows that the proportion of the respondents with medium level of perception is higher than that of other respondents with low and high level of perception towards climate change.

\section{Factor Associated with Perception of Farme rs towards Climate Change}

This unit shows the different factors associated with farmer's perception level towards climate change. For this, chi-squared test was applied taking farmer's perception level as dependent variable and other socio-economic variables as independent variables.

Table 8

Factors Associated with Farmer's Perception Level towards Climate Change

\begin{tabular}{|c|c|c|c|c|c|c|c|c|}
\hline \multirow[t]{3}{*}{ Variables } & \multicolumn{8}{|c|}{ Farmer's Perception Level towards Climate change } \\
\hline & \multicolumn{2}{|c|}{ Low } & \multicolumn{2}{|c|}{ Medium } & \multicolumn{2}{|c|}{ High } & \multicolumn{2}{|c|}{ Total } \\
\hline & Number & Percent & Number & Percent & Number & Percent & Number & Percent \\
\hline \multicolumn{9}{|l|}{ Age } \\
\hline $\begin{array}{l}\text { Up to } 60 \\
\text { years }\end{array}$ & 23 & 10.6 & 122 & 56.5 & 17 & 7.9 & 162 & 75.0 \\
\hline
\end{tabular}




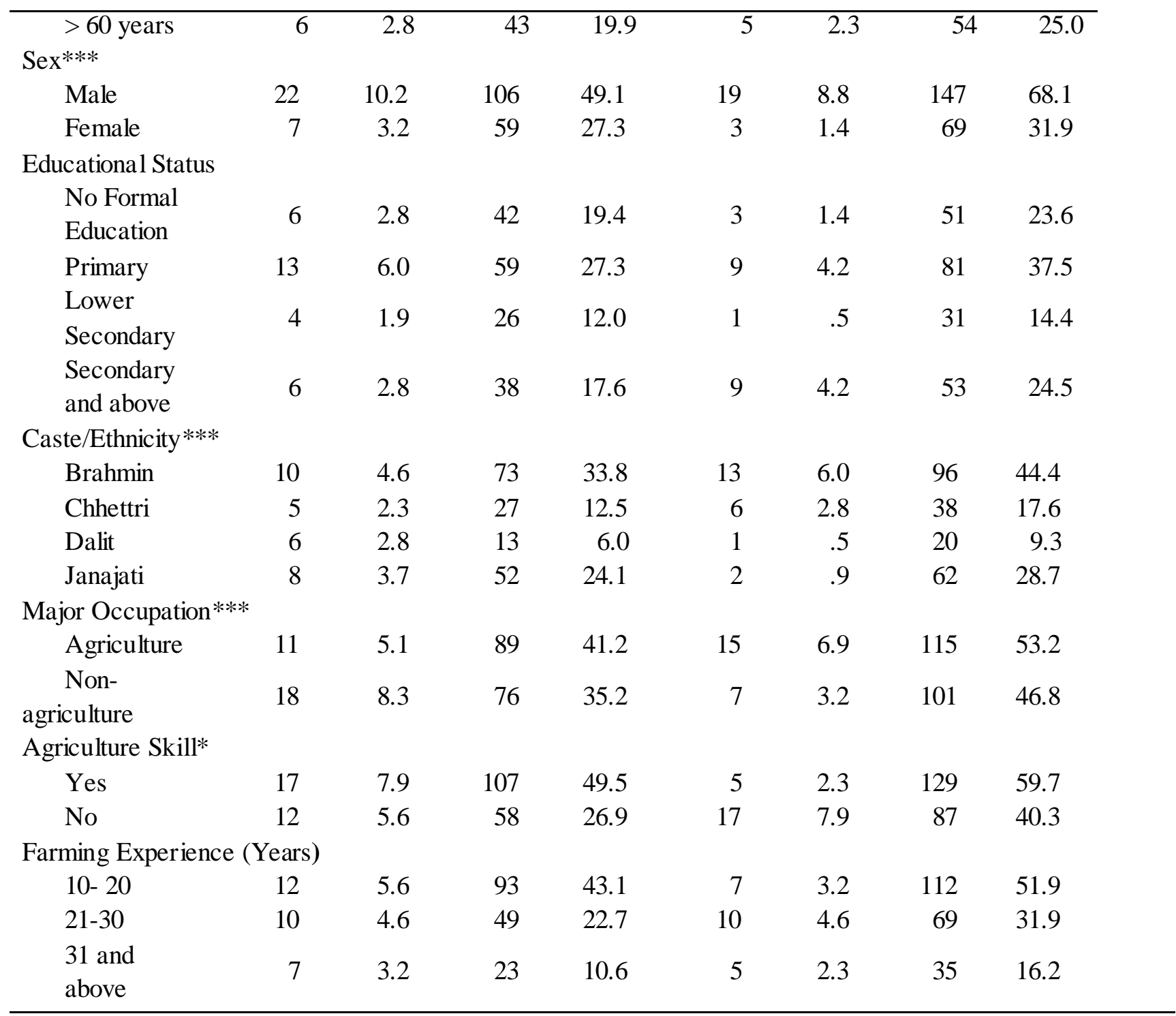

Note: ** significant at the $5 \%$ level of significance, *** significant at the $1 \%$ level of significance, $\mathrm{P}$-value is based on chi-squared test Source: Field survey, 2018

It is found that there is significant association of farmers' perception level towards climate change with agriculture skill of the respondents at one percent level of significance $(\mathrm{P}<0.01)$. This result is same with the study of Udin et al. (2017). Further, there is significant association of farmers' perception level towards climate change with Caste/Ethnicity, major occupation and sex at ten percent level of significance $(\mathrm{P}<0.1)$. Whereas, there is no any significant association of farmers' perception level towards climate change with age of the respondents, educational status of the 
respondents(which is contradictory with the study Mustapha et al., 2012, Ndambiri et al., 2012, Amdu et al., 2013, Akanda and Howlader, 2015 and Udin et al., 2017) and farming experience of the respondents( which is in contradiction with the study of Udin et al.(2017). It shows that agriculture skill, sex, caste/ethnicity and major occupation of the respondents are the major factors associated with farmers' perception level towards climate change. However there is no any significant effect of age, educational status and farming experience in farmers' perception level towards climate change.

\section{Conclusion}

The majority of the respondents perceivedincrease in average annual temperature, increase in average annual summer hotness, decrease in average annual rainfall, no change in average annual draught incidents, no change in flood incidents, no change in water availability to irrigate and increase in average number of pest and plant disease attack.

Further it is concluded that agriculture skill, sex, caste/ethnicity and major occupation of the respondents are the major factors associated with farmers' perception towards climate change. So, the government should lunch some trainees regarding agricultural skills and the farmers themselves should be aware about agricultural skills to increase their perceived level towards climate change.

\section{Acknowledgement}

I would like to acknowledge the students of School of Development and Social Engineering, Pokhara University, Rajan Pun, Bishwa Prakash Bhattarai and Yeknath Acharya for their valuable effort during data collection. Further, I would like to acknowledge Pokhara University Research Center (PURC), Pokhara University for providing grant to do this research.

\section{References}

Agrawal, A., McSweeney., C., \& Perrin, N. (2008). The Role of Local Institutions in Adaptation to Climate Change. Paper prepared for the Social Dimensions of Climate Change (p. 65). Social Development Department, the World Bank, Washington DC.

Akanda, M.G.R. and Howlader, M.S. (2015). Farmers' Perception of Climate Change Effects on Agriculture at GalachipaUpazila under Patuakhali District of Bangladesh. Global Journal of Science Frontier Research, 15, 31-39. 
Amdu, B., Ayehu, A. \& Deressa, A. (2013).Farmers' Perception and Adaptive Capacity to Climate Change and Variability in the Upper Catchment of Blue Nile, Ethiopia. The African Technology Policy Studies Network (ATPS), Nairobi.

Arbuckle, J., J. G., Morton, L. W., \& Hobbs, J. (2013). Farmer beliefs and concerns about climate change and attitudes toward adaptation and mitigation: Evidence from Iowa. Climatic Change. http://dx.doi.org/10.1007/s10584-013-0700-0.

Byg, A., \& Salick, J. (2009). Local perspectives on a global phenomenon-Climate change in Eastern Tibetan villages. Global Environmental Change, 19, 156-166.

CBC (2011). Environment Statistics of Nepal. Central Bureau of Statistics. Kathmandu.

Deressa, T. T., Hassan, R. M., \&Ringler, C. (2011).Perception of and adaptation to climate change by farmers in the Nile basin of Ethiopia.Journal of Agricultural Science, 149, 2331.http://dx.doi.org/10.1017/S0021859610000687.

Easterling et al.(2007). Observations: Surface and Atmospheric Climate Change. Proc Natl AcadSci USA.

Fosu-Mensah, B. Y., Vlek, P. L. G., \& Manschadi, A. M. (2010). Farmers' Perception and Adaptation to Climate Change; A Case Study of Sekyedumase District in Ghana. Paper presented at Tropentag 2010 "World Food System-A Contribution from Europe". 14-16th September, 2010, Zürich, Switzerland.

Gbetibouo, G. A. (2009). Understanding farmers' perceptions and adaptations to climate change and variability: the case of the Limpopo basin, South Africa. IFPRI discussion paper 00849. Washington, DC: IFPRI. Available: Www.fao.org/fileadmin/user_upload/.../docs/ifpri_limpopo dp00849.pdf. Visited on 24/04/2014.

Gitay et al. (2001). Crop Ecosystem Responses to Climatic Change. Amsterdam, Elsevier Publication.

Haque, A., Yamamoto, S. S., Malik, A. A., \&Sauerborn, R. (2012). Households' perception of climate change and human health risks: A community perspective. Environmental Health, 11(1), 1-12. http://dx.doi.org/10.1186/1476-069X-11-1.

IPCC.(2007). Summary for Policy makers. In: Climate Change 2007: Impacts, Adaptation and Vulnerability. Contribution of Working Group II to the Fourth Assessment Report of the Intergo vernmental Panel on Climate Change, Cambrid ge. 
Ishaya, S., \& Abaje, I. (2008).Indigenous people's perception on climate change and adaptation strategies in Jema'a local government area of Kaduna State, Nigeria. Journal of Geography and Regional Planning, 1(8), 138-143.

Kashaigili, J.J., Levira, P., Liwenga, E. \& Mdemu, M.V. (2014).Analysis of Climate Variability, Perceptions and Coping Strategies of Tanzanian Coastal Forest Dependent Communities. American Journal of Climate Change, 3, 212-222. http://dx.doi.org/10.4236/ajcc.2014.32020.

Lema, M., \& Majule, A. (2009). Impacts of climate change, variability and adaptation strategies on agriculture in semi arid areas of Tanzania: The case of Manyoni District in Singida Region, Tanzania. African Journal of Environmental Science and Technology, 3 (8), 206-218.

Maddison, D. (2006). The perception of and adaptation to climate change in Africa.Discussion Paper Series No. 10. Centre for Environmental Economics and Policy in Africa (CEEPA).

Maharjan, V., Sigdel, E. R., Sthapit, B. R., \&Regmi, B. R. (2011). Tharu community's perception on climate changes and their adaptive initiations to withstand its impacts in Western Terai of Nepal. International NGO Journal, 6 (2), 35-42.

Malla, G. (2008). Climate change and its impact on Nepalese agriculture. The Journal of Agriculture and Environment, 9, 62-71.

Mertz, O., Mbow, C., Reenberg, A., \&Diouf, A. (2009). Farmers' perceptions of climate change and agricultural adaptation strategies in rural Sahel. Environmental Management, 43 (5), 804-16. http://dx.doi.org/10.1007/s00267-008-9197-0.

Mustapha, S.B., Sanda, A.H. \&Shehu, H. (2012) Farmers' Perception of Climate Change in Central Agricultural Zone of Borno State, Nigeria. Journal of Environment and Earth Science, 2, 21-28.

Mutekwa, V. T. (2009). Climate change impacts and adaptation in the agricultural sector: the case of smallholder farmers in Zimbabwe. Journal of Sustainable Development in Africa, 11 (2), 237-256.

Ndamani, F. \& Watanabe, T. (2015). Farmers' perceptions about adaptation practices to climate change and barriers to adaptation: A micro-level study in Ghana. Water, 7 (9), 4593-4604.

Ndambiri, K., Ritho, C., Mbogoh, G., Ng'ang'a, I., Muiruri, J., Nyangweso, M., Kipsat, J., Omboto, I., Ogada, O., Kefa, C., Kubowon, C. \& Cherotwo, H. (2012) Analysis of Farmers' 
Perceptions of the Effects of Climate Change in Kenya: The Case of Kyuso District. Journal of Environment and Earth Science, 2, 74-83.

NAPA. (2010). Nepal's National Adaptation Programme of Action. Ministry of Environment, Kathmandu, Nepal.

Odjugo, P. A. O. (2010). Adaptation to Climate Change in the Agricultural Sector in the Semi-arid Region of Nigeria. Second International Conference: Climate, Sustainability and Development in Semi-arid Regions, Fortaleza - Ceará, Brazil.

Paavola, J. (2008). Livelihoods, vulnerability and adaptation to climate change in Morogoro, Tanzania. Sustainability Research Institute (SRI), School of Earth and Environment, University of Leeds, Leeds LS2 9JT, UK (pp 642-654).

Salau, E. S., Onuk E. G., \& Ibrahim, A. (2012). Knowledge, Perception and Adaptation Strategies to Climate Change among Farmers in Southern Agricultural Zone of Nasarawa State, Nigeria. Journal of Agricultural Extension, 16 (2), 199-211.

Satyal, V.R. (2010). Agriculture in Decline. Economic Journal of Development Issues 11 \& 12 (12), 144-157.

Uddin, M. N., Bokelmann, W. \& Dunn, E.S. (2017). Determinants of Farmers' Perception of Climate Change: A Case Study from the Coastal Region of Bangladesh. American Journal of Climate Change, 6, 151-165. https://doi.org/10.4236/ajcc.2017.61009. 